\title{
APPLIED PILOT-SCALE STUDIES ON CERAMIC MEMBRANE PROCESSES FOR THE TREATMENT OF WASTEWATER STREAMS
}

\author{
A. PAGANA \\ K. STOITSAS \\ V.T. ZASPALIS*
}

Selected from papers presented in $9^{\text {th }}$ International Conference on Environmental Science and Technology (9CEST2005)

1-3 September 2005, Rhodes island, Greece

\author{
Laboratory of Inorganic Materials \\ Chemical Process Engineering Research Institute \\ Center for Research and Technology-Hellas \\ P.O. Box 361, 57001 Thessaloniki, Greece
}

*to whom all correspondence should be addressed e-mail: zaspalis@cperi.certh.gr

\begin{abstract}
Asymmetric multilayer $\mathrm{Al}_{2} \mathrm{O}_{3}$ ceramic membranes with pore sizes ranging from 3 to $500 \mathrm{~nm}$ are synthesized in tubular form with external diameter of $14 \mathrm{~mm}$, internal diameter of $8 \mathrm{~mm}$ and length of $340 \mathrm{~mm}$. The membrane synthesis took place on commercially available supports, with the dip-coating technique either from aloumina particle suspensions or from boehmite sols.

The membranes are subsequently mounted in a pilot-scale module able to accept six specimens, and used in micro- and ultra- filtration experiments for the purification of aqueous streams from suspended solids. The experimental module is equipped with a back-flushing circuit that can be activated on demand to prevent the fouling of the membranes and the associated reduction in permeability.

For the microfiltration experiments membranes with $100 \mathrm{~nm}$ pore size are used. In the case of an aqueous solid suspension with a concentration of 0.1 to $1 \mathrm{wt} . \%$ consisting of solid particles with an average size of $0.5 \mu \mathrm{m}$, complete solid rejection is observed. The process has a capability of treating $0.8 \mathrm{~m}^{3}$ of feed per hour per square meter of membrane surface under an average pressure difference of $3 \times 10^{5} \mathrm{Nt} \mathrm{m}^{-2}$. The fouling of the membranes can be quite effectively reduced by back flushing at regular time intervals. Under complete retentate recycling conditions, more than $95 \%$ of the feed volume can be recovered as microparticle free water.

For the ultrafiltration experiments membranes with $3 \mathrm{~nm}$ pore sizes are used. In the case of an aqueous solid suspension of nanoparticles with a concentration of 0.1 to $1 \mathrm{wt} . \%$ consisting of solid particles with sizes of $20-30 \mathrm{~nm}$ the rejection was also almost complete. The process has in this case a capability of treating $0.16 \mathrm{~m}^{3}$ of feed per hour per square meter of membrane surface under an average pressure difference of $3 \times 10^{5} \mathrm{Nt} \mathrm{m}^{-2}$. Fouling appears not to cause serious permeability drop in this case probably because even after the nanoparticle deposition the membrane hydraulic resistance is the permeability determining step. Almost the entire feed volume can be recovered as nanoparticle free water under complete retentate recycling conditions.

Purification experiments are also performed in olive oil mill wastewater. Best results are achieved by using a two step membrane process with gradually decreasing pore size. Although complete rejection of solids and significant reduction of the $\mathrm{BOD}_{5}$ and phenol content of the wastes is achieved, the very low permeability is the main draw back of the process.
\end{abstract}

KEYWORDS: ceramic membranes, microfiltration, nanofiltration, water purification 


\section{INTRODUCTION}

The demand of, not always sufficiently available, ground and/or surface water, is expected to increase in the future. Therefore alternative sources of water among of which wastewater will gain more importance compared to the more traditional water sources. Waste water reuse after purification does not only help to overcome water shortages, but it also decreases the volume of wastewater to be discharged. The decrease, by pretreatment, of the volume or harmful loading of waste streams is of high importance in view of new legislations for waste discharge. Application examples are already published in literature [e.g.1].

Membrane filtration is a technology practiced successfully for many decades, with obvious technical and economical feasibilities [2,3]. Porous ceramic membranes consist an important membrane category that is particularly of interest in applications where high chemical or thermal stability is required. However, the choice of the right membrane material characteristics and process parameters depends always on the specific application.

In this article the results of the large area synthesis and pilot-scale experiments for porous ceramic membranes are reported for three case studies: I) purification of water from suspended microparticles (i.e. $d_{50} \sim 0.5 \mu \mathrm{m}$ ), II) purification of water from suspended nanoparticles (i.e. $d_{50} \sim 30 \mathrm{~nm}$ ) and III) treatment of olive oil refinery wastewater.

\section{EXPERIMENTAL}

\subsection{Membrane Synthesis}

In the general form the membrane is an asymmetric 4-layer in which the first layer functions as support the third as a microfiltration layer (pore sizes 100 or $200 \mathrm{~nm}$ depending on the firing temperature) and the fourth as an ultrafiltration layer with pore size of 3 to $5 \mathrm{~nm}$. The second layer (pore size $500 \mathrm{~nm}$ ) serves to bridge the gap between the macroporous support and the microfiltration layer. The fourth layer is synthesised by a process in which stable sols of boehmite are slip-cast onto the third-layer system. The slip-casting procedure is followed by drying and calcination at $600{ }^{\circ} \mathrm{C}$ for the formation of the final structure of $\mathrm{Y}-\mathrm{Al}_{2} \mathrm{O}_{3}$. Boehmite sol is prepared by hydrolysis of aluminum tri-sec-butylate at a temperature of $80^{\circ} \mathrm{C}$. One liter of water is used per mole of alkoxide. The sol is peptized with 0.05 mol $\mathrm{HNO}_{3}$ per mole alkoxide [4-6]. Typical nitrogen adsorption-desorption isotherm of $\mathrm{y}-\mathrm{Al}_{2} \mathrm{O}_{3}$ and the corresponding pore size distribution are shown in Fig. 1.

The macroscopic and microscopic characteristics of the membranes are shown in Fig 2.
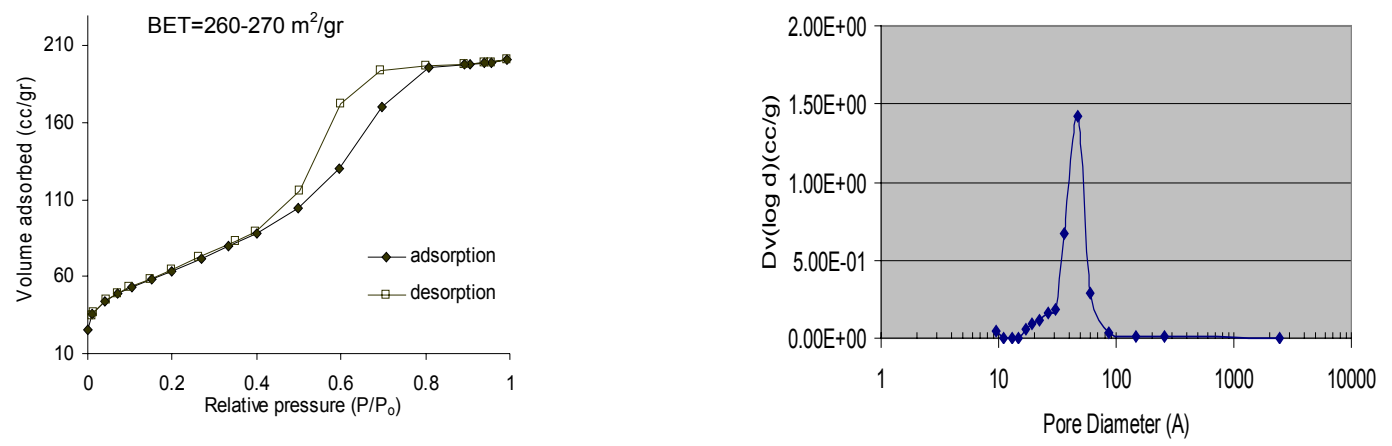

Figure 1. Nitrogen adsorption-desorption isotherm and pore size distribution of $\mathrm{y}-\mathrm{Al}_{2} \mathrm{O}_{3}$ membranes 

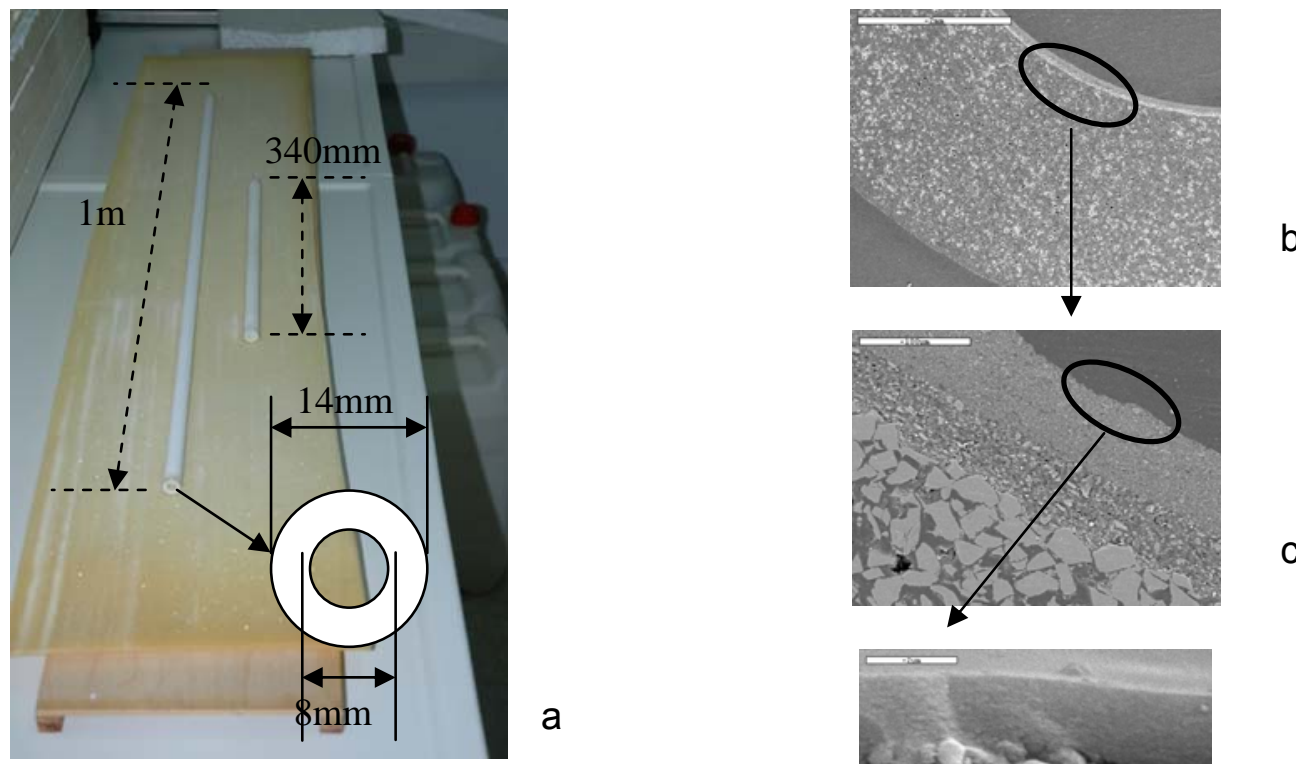

b

C

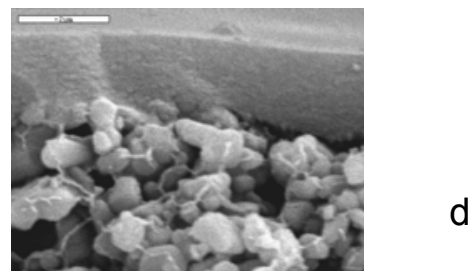

Figure 2. Photograph of the membrane specimens (a), scanning electron microscopy pictures of a cross section (b,c,d)

For the microfiltration experiments described in the following paragraphs the three-layer system is used, while for the nanofiltration the complete four-layer system is used.

\subsection{Experimental apparatus}

The flow diagram of the filtration module is shown in Fig. 3 . The unit employs six membrane specimens with a length of $340 \mathrm{~mm}$ and a total useful separation area of $0.05 \mathrm{~m}^{2}$. The maximum pressure inside the membrane tubes is 3 bar. The recycle ratio can be regulated through the control valve (Fig. 3). The unit has also a back-flushing circuit, the activation frequency and duration time of which can be programmed. Back flushing vessel is filled with permeate during normal operation. Mixture of permeate and air under pressure is then used as membrane cleaning fluid during the reverse (back-flushing) operation.

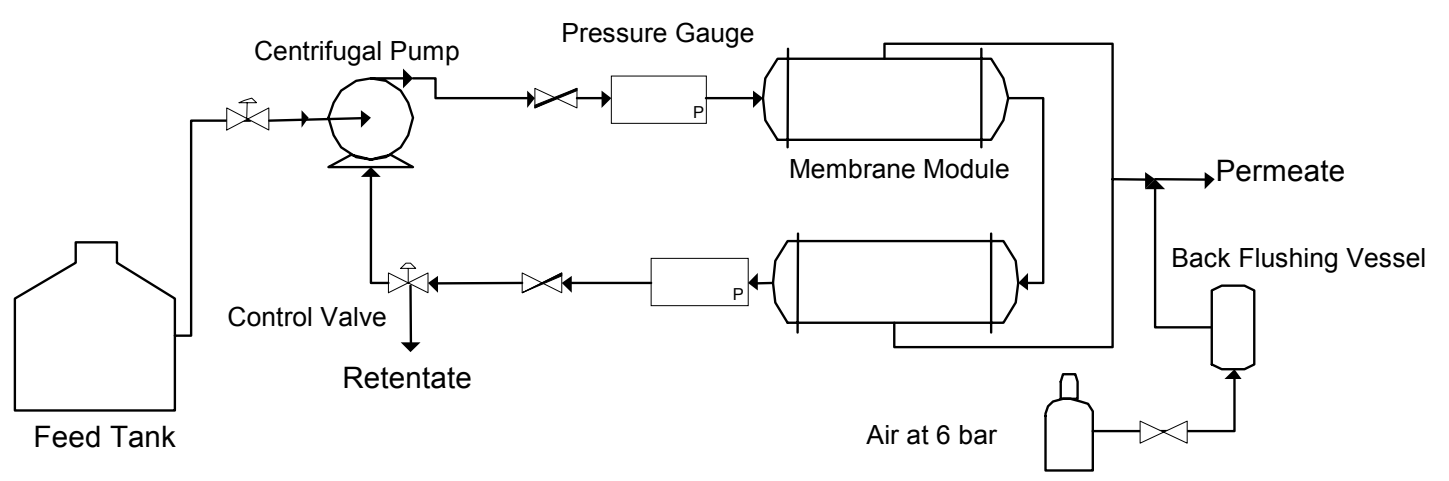

Figure 3. Flow diagram of the membrane filtration module

\section{RESULTS AND DISCUSSION}

\subsection{Microfiltration}

A typical suspension for the feed of microfiltration experiments is made as follows. A total weight of 500gr powder is made by mixing $\mathrm{Fe}_{2} \mathrm{O}_{3}, \mathrm{MnO}$ and $\mathrm{ZnO}$ with a molar ratio of 2.1/1/1 correspondingly. The mixture is then prefired under air to $800^{\circ} \mathrm{C}$ for $5 \mathrm{hr}$. The prefired powder 
is ball milled in $50-50$ solid-water wt.\% aqueous suspensions with 14 and $4 \mathrm{~mm}$ stainlesssteel ball diameters for $15 \mathrm{hr}$. Adding clean water controls the final concentration of the suspensions. The particle size distribution of a suspension with a concentration of 1 wt.\% $\mathrm{Fe}_{2} \mathrm{O}_{3}$ solids was measured with laser scattering experiments Fig. 4. As can be seen, the feed contains particles that cover a size range from 0.1 to $10 \mu \mathrm{m}$ with an average of $0.5 \mu \mathrm{m}$.

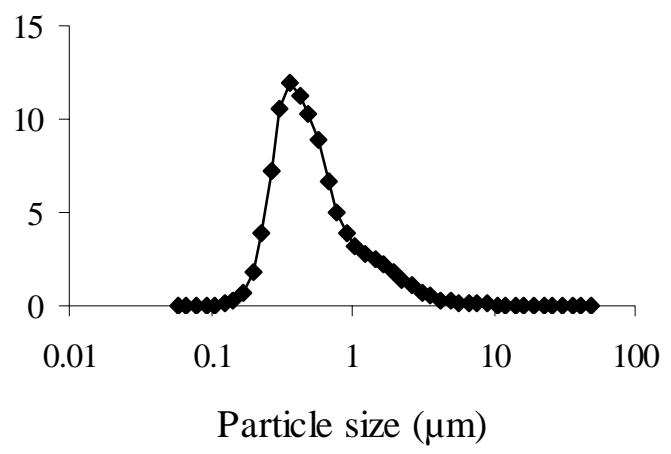

Figure 4. Particle size distribution of the $\mathrm{Fe}_{2} \mathrm{O}_{3}$ solid particles in the feed stream

Microfiltration experiments revealed that the solids rejection is practically complete since no laser scattering measurements are possible on the membrane filtration product. The absence of solids in the permeate side is confirmed by turbidity experiments. Specifically the turbidity of the permeate was measured at value of around 0.5 NTU the same with this of the clean water.

In Fig. 5 the permeate (i.e. solid free water) flux is shown as a function of time. The fluxes were measured with graduated volumetric cylinders and a stopwatch. The retentate flux remains constant during the operation at $365 \mathrm{ml} / \mathrm{min}$.

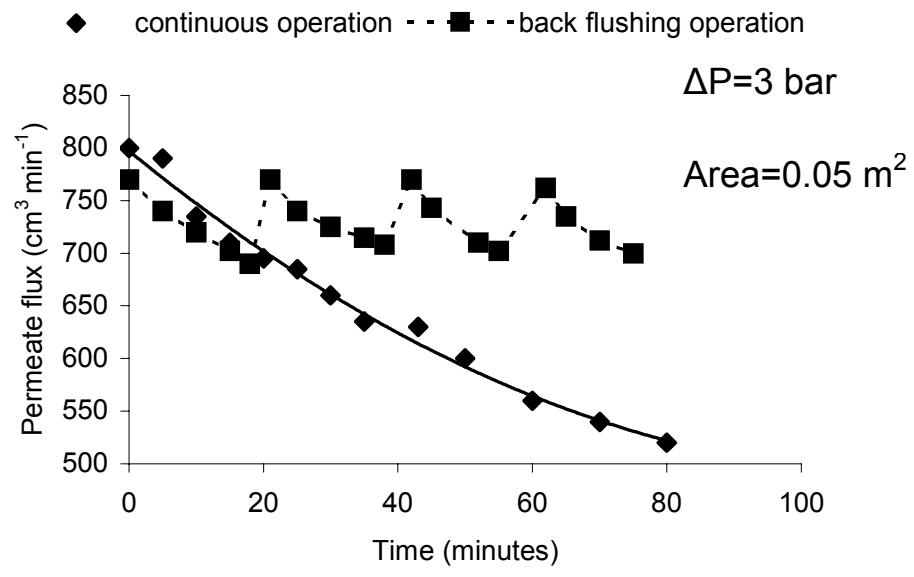

Figure 5. Permeate stream flux as a function of operation time for continuous and back flushed operations

In the case that no back flushing is used the permeate flux continues to decline even after 1 $\mathrm{hr}$ of filtration. The flux decline can be caused by the continuous infiltration of fine particulate matter into the concentration polarization layer or by the compaction of the layer $[7,8]$. The penetration of particles in the porous structure of the membrane is excluded since in the case that back flushing is used the permeate flux is completely restored [9]. As a result the decline of the permeate flux is caused by the compaction of the filter cake. This compaction reduces the porosity of the cake, which in turn increases the hydraulic resistance to flux [10].

In Table 1 the process results are shown for an experiment with back flushing every 20 min for $30 \mathrm{sec}$ under complete retentate recycling. More than $95 \%$ of the feed volume can be recovered in the form of solids free water. 
Table 1. Characteristic process features for microfiltration experiments under complete retentate recycling

\begin{tabular}{|c|c|}
\hline \multicolumn{2}{|c|}{ 100\% Retentate Recycling Conditions } \\
\hline Feed volume: & 50 It (100\%) \\
\hline Solids Content: & 1 wt. $\%$ \\
\hline Permeate volume: & 48 It (96\%) \\
\hline Solids Content: & 0 wt. $\%$ \\
\hline Residue: & 2 It $(4 \%)$ \\
\hline Solids Content: & $25 \%$ \\
\hline Av. Permeate flux: & $700 \mathrm{ml} \mathrm{min}{ }^{-1}$ \\
\hline Process time: & $71 \mathrm{~min}$. \\
\hline
\end{tabular}

\subsection{Ultrafiltration}

Aqueous suspensions of nanoparticles $\mathrm{y}-\mathrm{Fe}_{2} \mathrm{O}_{3}$ with a concentration of 1 wt. $\%$ are used as feed for the ultrafiltration experiments. In Fig. 6 a high-resolution transmission electron microscopy picture is shown of the $\mathrm{Fe}_{2} \mathrm{O}_{3}$ nanoparticles. These pictures calculate an average particle size of $30 \mathrm{~nm}$. To avoid agglomeration of these particles the feed is immersed in an ultrasonic bath for $15 \mathrm{~min}$. Soft agglomerates can be broken up with the help of ultrasonic energy.
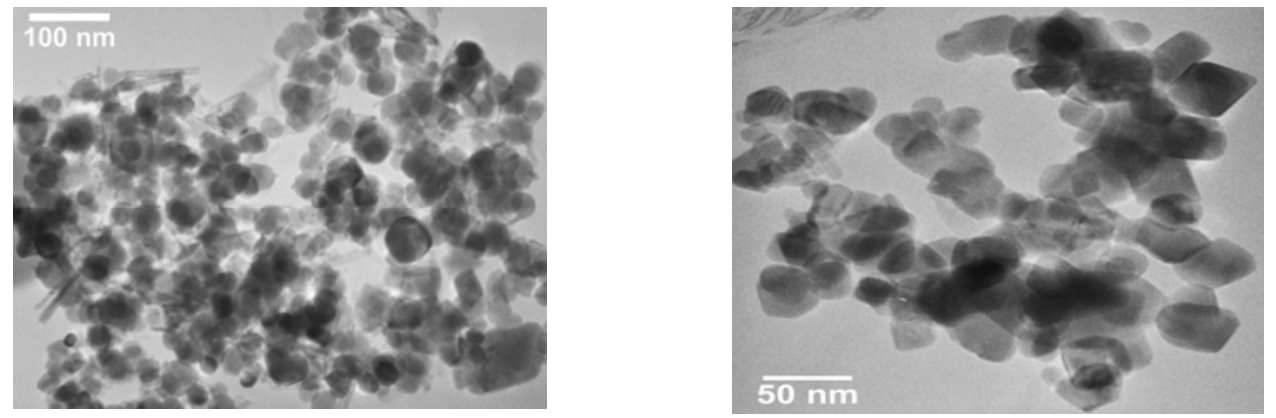

Figure 6. TEM picture of the nanoparticles in the feed stream

Complete solid retention is appeared by using the 4-layer nanoporous $\mathrm{Y}-\mathrm{Al}_{2} \mathrm{O}_{3}$ membrane system. Turbidity experiments confirm the absence of solids in the permeate side.

The permeate flux as a function of time in the case of ultrafiltration experiments is shown in Fig. 7 under continuous operation. Unlike the microfiltration case no permeate flux reduction because of fouling is obtained in this case. An imperceptible reduction is observed for the first $10 \mathrm{~min}$ probably by the reduction of the porosity of $\mathrm{y}-\mathrm{Al}_{2} \mathrm{O}_{3}$ layer by the deposition of nanoparticles on its surface.

The explanation for unsubstantial reduction of the flux can be most probably found in the fact that even after the deposition of the filter cake the permeability of the system, that can be considered to consist of hydraulic resistances connected in series, is still controlled by the highly tortuous card packed structure of the sol-gel made nanoporous membrane [4]. In Fig. 8 scanning electron microscopy pictures are shown of the nanoparticle filter cake formed on top of the membrane surface. 


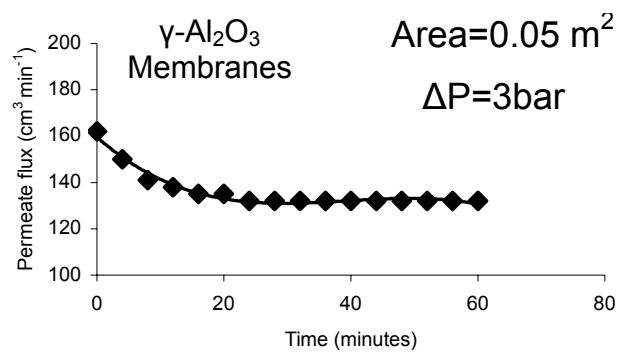

Figure 7. Permeate stream flux as a function of operation time
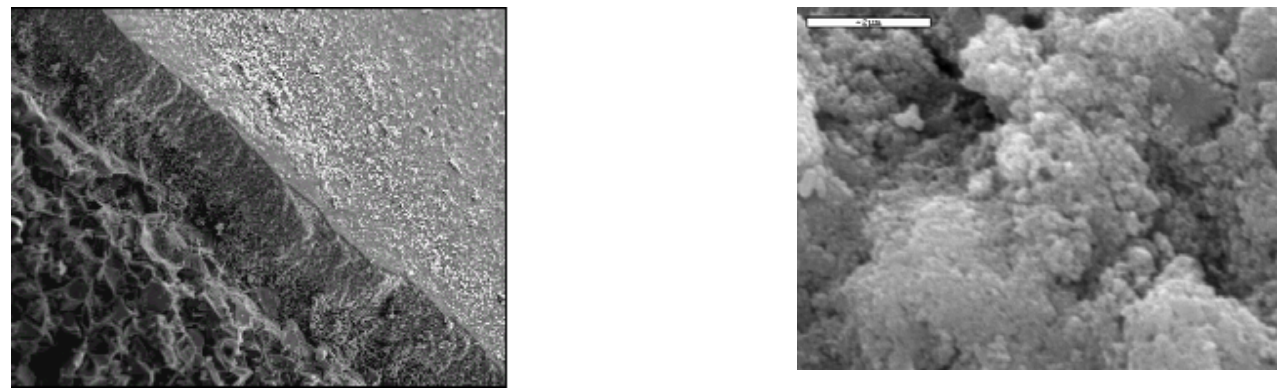

Figure 8. SEM image of the nanoparticle filter cake formed on the membrane surface

Nanoparticles retention may find a large number of interesting applications nowadays such as e.g. recovery of $\mathrm{TiO}_{2}$ nanoparticles that are used for photocatalysis process either in decomposition of organic loads in waste streams or for degradation of pharmaceutical residues [11-13]. The recovery of nanoparticles of iron oxide that adsorb toxic ions such as arsenic, is a promising process for purification of water from hazardous contaminants [14,15].

\subsection{Olive oil mill wastewater}

Oil refinery wastes are well known for their highly toxic and environmentally harmful character [16]. In Fig. 9 the membrane process scheme used to treat regular cold compression olive oil mill wastewater is shown. Analysis data are shown in Table 2. As can be seen from Table 2 the organic loading of the stream is strongly improved below the discharge requirements of biologic purification plants. The main disadvantage of the system is the low permeate flux that makes the size of a real unit economically questionable.

Back flushing appears not to bring significant advantages since pore clogging occurs probably from oil layers adhered to the pore walls. Under complete retentate recycling conditions $50 \%$ of the feed volume could be recovered as dischargeable waste stream with the properties indicated in the last row of Table 2. The regeneration of the membranes was possible by heating the elements at elevated temperatures (i.e. $>300^{\circ} \mathrm{C}$ ) to burn the organic residues of the filter cake.

Table 2. Analysis results of the feed and permeate streams of the process shown in (the permeate fluxes refer to an average pressure difference of $3 \times 10^{5} \mathrm{Nt} \mathrm{m}^{2}$ )

Fig. 9

\begin{tabular}{|c|c|c|c|}
\hline Process Stream & BOD $_{5}$ (mgr/lt) & Phenols (mgr/lt) & Flux $\mathrm{m}^{3} \mathrm{hr}^{-1} \mathrm{~m}^{-2}$ \\
\hline Untreated feed & 3900 & 890 & \\
\hline Permeate 1 (Fig.9) & 2337 & 400 & 0.2 \\
\hline Product (Fig.9) & 1514 & 160 & 0.01 \\
\hline
\end{tabular}




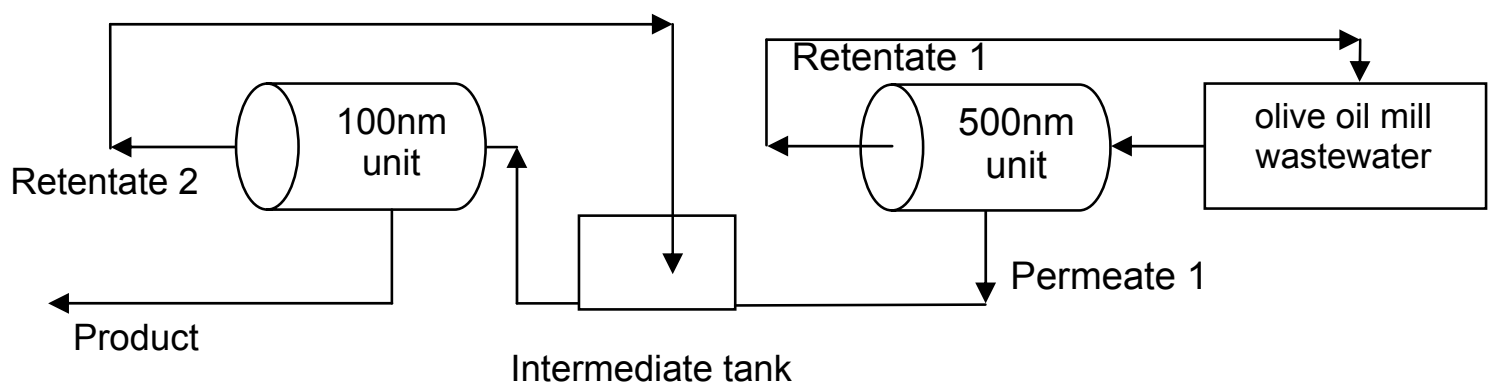

Figure 9. Schematic flow diagram of the membrane process used to treat olive oil mill wastewater

\section{CONCLUSIONS}

Pilot-scale experiments on asymmetric multilayer porous ceramic membrane modules revealed:

- Complete microparticle rejection of wastewater streams at an average solids free water production of $0.8 \mathrm{~m}^{3} \mathrm{hr}^{-1} \mathrm{~m}^{-2}$ with operation under an average pressure difference of $3 \mathrm{x}$ $10^{5} \mathrm{Nt} \mathrm{m}{ }^{-2}$.

- Complete nanoparticle rejection of wastewater streams at an average solids free water production of $0.16 \mathrm{~m}^{3} \mathrm{hr}^{-1} \mathrm{~m}^{-2}$ with operation under an average pressure difference of $3 \mathrm{x}$ $10^{5} \mathrm{Nt} \mathrm{m}^{-2}$.

- Olive oil mill wastewater can be upgraded with reduction of its $\mathrm{BOD}_{5}$ content by $61 \%$ and its concentration in phenols by $82 \%$ at an average dischargeable waste production of 0.01 $\mathrm{m}^{3} \mathrm{hr}^{-1} \mathrm{~m}^{-2}$ with operation under an average pressure difference of $3 \times 10^{5} \mathrm{Nt} \mathrm{m^{-2 }}$.

\section{ACKNOWLEDGEMENTS}

The financial support of the Greek Ministry of Development (Contract Nr: 01AKMON13) is gratefully appreciated.

\section{REFERENCES}

1. Roeleveld P.J. and Maaskant W. (1999) A feasibility study on ultrafiltration of industrial effluents, Wat. Sci. Technol., 39, 73-80.

2. Laîné J.M., Vial D. and Moulart P. (2000) Status after 10 years of operation-overview of UF technology today, Desalination, 131, 17-25.

3. Van-der-Bruggen B. and Vandecasteele C. (2002) Distillation vs. membrane filtration: overview of process evolutions in seawater desalination, Desalination, 143, 207-218

4. Kikkinides E.S., Stoitsas K.A. and Zaspalis V.T. (2003) Correlation of structural and permeation properties in sol-gel made nanoporous membranes, J. Coll. Interf. Sci., 259, 322330.

5. Zaspalis V.T., Van Praag W., Keizer K. (1992) Synthesis and characterization of primary alumina, titania and binary membranes, J. Mater. Sci., 27, 1023-1035.

6. Uhlhorn R.J.R., Keizer K., Burggraaf A.J., (1992) Gas-transport and separation with ceramic membranes.1. Multilayer Diffusion and Capillary Condensation, J. Membr. Sci., 66, 259-269.

7. Muhammad H., Malack Al. Anderson G.K., (1996) Coagulation-crossflow microfiltration of domestic wastewater, J. Membr. Sci., 121, 59-70.

8. Hsieh H.P., (1996) Inorganic membranes for separation and reaction. Membrane Science and Technology Series, 3'.

9. Laitinen N., Kulovaara M., Levänen E., Luonsi A., Teilleria N., Nyström M., (2002) Ultrafiltration of stone cutting mine waste water with ceramic membranes-a case study, Desalination, 149, 121-125.

10. Vyas H.K., Bennett R.J., Marshall A.D., (2000) Influence of operating conditions on membrane fouling in crossflow microfiltration of particulate suspensions. Inter. Dairy. J., 10, 477-487.

11. Chin S.S., Chiang K. and Fane A.G., (2005) The stability of polymeric membranes in $\mathrm{CiO}_{2}$ photocatalysis process, J. Membr. Sci., In Press. 
12. Liu I., Lawton L.A., Bahnemann W. and Robertson K.J., (2005) The photocatalytic destruction of the cyanotoxin, nodularin using $\mathrm{TiO}_{2}$, Appl. Catal. B: Environ., 60, 245-252.

13. Doll T.E. and Frimmel F.H., (2005) Cross-flow microfiltration with periodical back-washing for photocatalytic degradation of pharmaceutical and diagnostic residues-evaluation of the longterm stability of the photocatalytic activity of $\mathrm{TiO}_{2}$. Water Research, 39, 847-854.

14. Pagana A., Zaspalis V., (2006) Removal of arsenic from water by iron oxide nanoparticles and nanofiltration ceramic membranes, 4th Eastern Mediterranean Chemical Engineering Conference (EMCC-4), Israel.

15. Daus B., Wennrich R. and Weiss H., (2004) Sorption materials for arsenic removal from water: a comparative study. Water Research, 38, 2948-2954.

16. Wake H., (2005) Oil refineries: a review of their ecological impacts on the aquatic environment, Estuar. Coast. \& Shelf Sci., 62, 131-145. 